\title{
Genetic parameters for grain angle in 28-year-old Norway spruce progeny trials and their parent seed orchard
}

\author{
Henrik R. HALLINGBÄCK*, Gunnar JANSSON, Björn HANNRUP \\ Department of Plant Biology and Forest Genetics, Swedish University of Agricultural Sciences, PO Box 7080, 750 07, Uppsala, Sweden
}

(Received 12 July 2007; accepted 18 December 2007)

\begin{abstract}
-
- Sawn wood which acquires twist during drying is a substantial problem for the sawmill industry and is to a large extent caused by spiralled grain in the tree.

- In this study, the feasibility of using spiral grain angles as a selection trait in Norway spruce (Picea abies (L.) Karst) tree breeding and the extent of grain angle and its breeding values were investigated. Grain angles under bark and diameter were measured at breast height in three 28 -year-old Norway spruce progeny trials and in their parent seed orchard.

- The mean grain angle value was $1.76^{\circ}$ in the progeny trials and $1.84^{\circ}$ in the seed orchard. Estimated genetic standard deviations for grain angle were almost $1^{\circ}$. Progeny trial heritabilities $\left(H^{2}>0.3\right)$ were larger than the seed orchard heritability $\left(H^{2}=0.24\right)$. Genotype by environment interaction among the progeny trials was negligible for grain angle. Progeny trial grain angles exhibited genetic correlation with seed orchard grain angles in the range 0.66 to 0.84 .

- Thus, mature wood grain angles are also under considerable genetic control, raising the opportunity to reduce the occurence of left-grained trees,
\end{abstract} which are prone to producing twisted wood.

spiral grain / shape stability / heritability / breeding / Picea abies

Résumé - Paramètres génétiques de l'angle du fil du bois étudiés dans des descendances d'épicéa commun âgés de 28 ans et chez leurs parents en verger à graines.

- Les déformations au séchage du bois scié sont un problème majeur pour l'industrie du bois et sont pour une large part causées par l'angle du fil du bois.

- Dans cette étude, nous avons étudié la possibilité d'utiliser l'angle du fil du bois comme critère de sélection pour l'amélioration génétique de cette propriété chez l'épicéa commun. Les angles du fil du bois sous écorce ainsi que le diamètre à $1,30 \mathrm{~m}$ ont été mesurés dans trois tests de descendances d'épicéa commun âgés de 28 ans et dans un verger à graines où sont localisés les parents.

- L'angle moyen du fil du bois était de $1,76^{\circ}$ dans les tests de descendances et de $1,84^{\circ}$ dans le verger à graines. L'écart-type génétique estimé pour $l^{\prime}$ 'angle du fil était de presque $1^{\circ}$. Les héritabilités estimées en tests de descendances $\left(H^{2}>0,3\right)$ étaient plus fortes que celle obtenue en verger à graines $\left(H^{2}=0,24\right)$. L'interaction $\mathrm{G} \times \mathrm{E}$ était négligeable entre tests de descendances. Les angles du fil obtenus en tests de descendances montraient une corrélation génétique de $0,66-0,84$ avec les angles obtenus en verger à graines.

- En conclusion, nous montrons que les angles du fil du bois mature sont sous contrôle génétique fort, ce qui permet d'envisager la réduction de la fréquence d'arbres à fil gauche, très sujets à produire du bois vrillé.

angle du fil du bois / stabilité du bois / héritabilité / amélioration génétique / Picea abies

\section{INTRODUCTION}

Shape stability is an important property for sawn wood used for joinery, veneer, glulam production, building construction and other wood products. Studs and boards with shape stability problems are prone to warping during the drying process in sawmills. Among different types of wood warp, especially twist makes studs and boards less valuable as structural timber and severely twisted pieces must be sorted and discarded [14]. While the culling of form defects improves product quality, they nonetheless represent a significant economic loss to the mill [26]. In Scandinavia, shape stability problems in Norway spruce (Picea abies (L.) Karst), primarily due to twist, result in

*Corresponding author: Henrik.Hallingback@vbsg.slu.se large economic losses to the building construction and sawmill industries $[14,22,26]$.

Shape stability of dried softwood studs and boards, especially the development of twist, is heavily influenced by spiral grain $[6,15]$. Spiral grain is the tangential inclination angle of wood fibres from the vertical stem axis. This phenomenon is not exceptional in conifers and the variation in grain angles is great among tree species and individual trees, and between annual rings within a tree [13].

In recent years, evidence has emerged that spiral grain is under strong genetic control. High heritability and substantial genetic variation have been observed for grain angle in several conifer species, e.g. Norway spruce $[2,10]$, Scots pine (Pinus sylvestris L.) [11], Sitka spruce (Picea sitchensis (Bong.) Carr) 
[12] and radiata pine (Pinus radiata D. Don) [4, 24]. In Norway spruce genotype-environment $(\mathrm{G} \times \mathrm{E})$ interaction for grain angle has not been significant $[2,11]$. Correlations between grain angle and growth and other wood properties have generally also been weak or not significant $[3,9,11]$. The high heritability and genetic variation suggests that the shape stability of Norway spruce sawn wood might be improved by selection and breeding for low grain angle.

Most conifers, like Norway spruce, produce increasing lefthanded grain angles in the first annual rings from pith. After 10 or so rings, the grain angle culminates and then slowly decreases, often resulting in right-handed grain angles at older ages $[13,16]$. The measurement height in the tree does not seem to influence this relationship greatly [5,23]. There are, however, trees that deviate from this pattern by producing annual rings where the left grain angle remains constant or even increases with cambial age. Several studies have shown that logs from such left-grained trees produce studs and boards that are particularly prone to twisting $[1,18]$.

Currently, methods of measuring grain angles in all annual rings from pith to bark either require the tree in question to be felled or require complicated and time-consuming measurements on diametrical increment cores. Faster, non-destructive methods used on standing trees only produce observations from the peripheral annual rings close to the bark, making the cambial age at the time of assessment a very important factor to consider $[13,24]$. Nonetheless, most research on genetic grain angle variation in Norway spruce, destructive as well as non-destructive, have hitherto focused on young material and consequently on juvenile wood grain angles [2, 10, 11].

The objective of this study was to investigate the feasibility of incorporating spiral grain as a selection wood property in a Norway spruce tree breeding programme. Especially important was the question of whether parent trees with high breeding values for left-handed grain angle in mature wood could be found. To answer these questions we estimated genetic parameters and breeding values for spiral grain under bark at breast height in a series of three 28-year-old full-sib progeny trials and a 48-year-old seed orchard containing the parent clones. Among Scandinavian genetic trials, these are considered to be relatively old and produce mature wood at breast height.

\section{MATERIAL AND METHODS}

\subsection{Genetic material}

The parents were Norway spruce plus-trees, phenotypically selected in natural stands for vigour, height, diameter and straightness, and for horizontal small-diameter branches. The origin of the plustrees was in the range of latitude $55^{\circ} 40^{\prime} \mathrm{N}-58^{\circ} 29^{\prime} \mathrm{N}$, longitude $12^{\circ}$ $17^{\prime} \mathrm{E}-15^{\circ} 10^{\prime} \mathrm{E}$ and at altitude $35-190 \mathrm{~m}$ a. s. 1 . Material from these plus-trees was grafted into a seed orchard in 1956. All ramets were randomised in single-tree plots with the restriction that neighbouring trees always had to be different clones. The initial spacing was approximately $4 \times 4 \mathrm{~m}$.

The progeny trials were derived from progenies from controlled crosses among 36 of the seed orchard parents. Each parent was represented in seven crosses according to a partial diallel mating design.
Table I. Site data at the time of investigation.

\begin{tabular}{lcccc}
\hline & \multicolumn{3}{c}{ Progeny tests } & $\begin{array}{c}\text { Seed orchard } \\
\text { Maglehem }\end{array}$ \\
\cline { 2 - 5 } & Vetlanda & Tönnersjö & Lönsboda & Magl' \\
\hline Latitude & $57^{\circ} 41^{\prime} \mathrm{N}$ & $56^{\circ} 66^{\prime} \mathrm{N}$ & $56^{\circ} 43^{\prime} \mathrm{N}$ & $55^{\circ} 77^{\prime} \mathrm{N}$ \\
Longitude & $15^{\circ} 15^{\prime} \mathrm{E}$ & $13^{\circ} 09^{\prime} \mathrm{E}$ & $14^{\circ} 33^{\prime} \mathrm{E}$ & $14^{\circ} 17^{\prime} \mathrm{E}$ \\
Altitude (m a. s. 1.) & 230 & 90 & 150 & 30 \\
No. growing seasons & 28 & 29 & 29 & 48 \\
No. trees measured & 949 & 785 & 567 & 352 \\
No. parents & 36 & 36 & 36 & 30 \\
No. families & 106 & 115 & 88 & - \\
No. blocks & 3 & 2 & 3 & - \\
Survival rate $(\%)$ & 93 & 91 & 85 & - \\
\hline
\end{tabular}

The progenies were randomised in single-tree plots, with each family represented by four progenies in each of 10 blocks. The seedlings were planted with a spacing of $2 \times 2 \mathrm{~m}$. The progeny trials and the seed orchard are located in southern Sweden (Tab. I).

\subsection{Field assessment}

In each of the progeny trials all trees in 2 or 3 blocks were measured at a time, when the trees had been 28 or 29 years in the field. For all sample trees, the breast height diameter $(\mathrm{DBH})$ and breast height grain angle under bark $\left(\mathrm{GA}_{\mathrm{ub}}\right)$ was measured. $\mathrm{GA}_{\mathrm{ub}}$ was measured with a wedge grain angle gauge, described by Hannrup et al. (2003). The wedge was gently hammered into the stem at the internode closest to breast height $(1.3 \mathrm{~m})$. Branches and burls were carefully avoided. Measurements from two opposite sides (north and south) of the stem were made and the mean was used as an estimate of $\mathrm{GA}_{\mathrm{ub}}$, thus eliminating the measurement error associated with a stem axis leaning from the vertical $[12,13]$. Grain inclination to the left following the tree stem upwards (left-handed grain) is denoted by positive angle values, whereas grain inclination to the right (righthanded grain) is indicated by negative values. When measuring Norway spruce material, removal of bark is unnecessary and the measurement could be done with little damage to the tree. One hundred seventy-six progeny trees out of 2477 (7\%) could not be measured due to having a DBH of less than $50 \mathrm{~mm}$ or having double stems.

Genetic thinning of the seed orchard in 1994 left only 30 clones of the original 36 clones, with the ramets of the remaining clones located in a random non-uniform pattern [20]. Sample trees were identified with the aim of obtaining measurements from at least 10 ramets per clone, distributed as widely as possible across the site. DBH and $\mathrm{GA}_{\mathrm{ub}}$ were measured on ramets using the same methods as in the progeny trials.

\subsection{Statistical analysis}

Statistical analysis of the progeny trials was first performed separately for individual sites using multivariate mixed linear models:

$$
\mathbf{y}=\mathbf{X}_{\mathbf{b}} \mathbf{b}+\mathbf{Z}_{\mathbf{p}} \mathbf{p}+\mathbf{Z}_{\mathbf{f}} \mathbf{f}+\mathbf{e}
$$

where $\mathbf{y}$ is the observation vector for the traits $\mathrm{DBH}$ and $\mathrm{GA}_{\mathrm{ub}}$; and $\mathbf{b}, \mathbf{p}, \mathbf{f}$ and $\mathbf{e}$ are the vectors of fixed block effects, random parent effects, random family effects and residuals, respectively. To estimate site-site genetic correlations, the same model was used, where $\mathbf{y}$ is 
the observation vector for one and the same trait measured at each site. Connecting effects to observations, design matrices $\mathbf{X}_{\mathbf{b}}, \mathbf{Z}_{\mathbf{p}}$ and $\mathbf{Z}_{\mathbf{f}}$ were used for fixed block effects, parent effects and family effects, respectively. All random effects were assumed to be independent and normally distributed with expectation of zero.

$$
\operatorname{Var}\left[\begin{array}{c}
\mathbf{p} \\
\mathbf{f} \\
\mathbf{e}
\end{array}\right]=\left[\begin{array}{ccc}
\mathbf{P} \otimes \mathbf{I}_{\mathbf{p}} & \mathbf{0} & \mathbf{0} \\
\mathbf{0} & \mathbf{F} \otimes \mathbf{I}_{\mathbf{f}} & \mathbf{0} \\
\mathbf{0} & \mathbf{0} & \mathbf{R} \otimes \mathbf{I}_{\mathbf{e}}
\end{array}\right]
$$

$\mathbf{P}, \mathbf{F}$ and $\mathbf{R}$ are variance-covariance matrices for parental, family and residual effects, respectively, while $\mathbf{I}_{\mathbf{p}}, \mathbf{I}_{\mathbf{f}}$ and $\mathbf{I}_{\mathbf{e}}$ are identity matrices. Restricted maximum likelihood estimates of variance and covariance components were performed using ASReml software [8].

For the statistical analysis of the seed orchard parents, a univariate model was used for each trait.

$$
y_{i j}=\mu+c_{i}+e_{i j}
$$

where $y_{i j}$ is the observation from the $j$-th ramet from the $i$-th clone; $\mu$ is the trait mean; $c$ is the random effect of the $i$-th clone; and $e$ is the residual.

Genetic correlations between the same trait in the progeny trials and in the seed orchard were calculated using an individual-tree mixed linear model:

$$
\mathbf{y}=\mathbf{X}_{\mathbf{b}} \mathbf{b}+\mathbf{Z}_{\mathbf{u}} \mathbf{u}+\mathbf{Z}_{\mathbf{f}} \mathbf{f}+\mathbf{e}
$$

where the observation vector $\mathbf{y}$ used individual tree observations from the progeny trials and seed orchard, respectively. $\mathbf{Z}_{\mathbf{u}}$ relates to records for individual trees and $\mathbf{u}$ to parental breeding values for individual trees. Random effects were assumed to be normally distributed with the expectation value at zero and structured as:

$$
\operatorname{Var}\left[\begin{array}{c}
\mathbf{u} \\
\mathbf{f} \\
\mathbf{e}
\end{array}\right]=\left[\begin{array}{ccc}
\mathbf{G} \otimes \mathbf{A} & \mathbf{0} & \mathbf{0} \\
\mathbf{0} & \mathbf{F} \otimes \mathbf{I}_{\mathbf{f}} & \mathbf{0} \\
\mathbf{0} & \mathbf{0} & \mathbf{R} \otimes \mathbf{I}_{\mathbf{e}}
\end{array}\right]
$$

$\mathbf{G}, \mathbf{F}$ and $\mathbf{R}$ are variance-covariance matrices for genetic, family and residual effects, respectively. $\mathbf{A}$ is the additive relationship matrix connecting the progeny trial trees to their seed orchard parent clones.

Finally, a multivariate model for the joint analysis of all progeny trials was used to obtain genetic parameters across sites and genetic breeding values for $\mathrm{DBH}$ and $\mathrm{GA}_{\mathrm{ub}}$ :

$$
\mathbf{y}=\mathbf{X}_{\mathbf{s}} \mathbf{s}+\mathbf{X}_{\mathbf{b}} \mathbf{b}+\mathbf{Z}_{\mathbf{p}} \mathbf{p}+\mathbf{Z}_{\mathbf{f}} \mathbf{f}+\mathbf{Z}_{\mathbf{w}} \mathbf{w}+\mathbf{e}
$$

where $\mathbf{s}$ is the fixed site effect; $\mathbf{w}$ is the random site-parent interaction effect; and the matrices $\mathbf{X}_{\mathbf{s}}$ and $\mathbf{Z}_{\mathbf{w}}$ connect these effects to the observations. Blocks were considered to be nested within sites. When using this model, all phenotypic data for each site was scaled to the same additive genetic variance, equating the mean of the scaled data to that of the raw data. All random effects were assumed to be independent and normally distributed with expectation of zero and structured as:

$$
\operatorname{Var}\left[\begin{array}{c}
\mathbf{p} \\
\mathbf{f} \\
\mathbf{w} \\
\mathbf{e}
\end{array}\right]=\left[\begin{array}{cccc}
\mathbf{P} \otimes \mathbf{I}_{\mathbf{p}} & \mathbf{0} & \mathbf{0} & \mathbf{0} \\
\mathbf{0} & \mathbf{F} \otimes \mathbf{I}_{\mathbf{f}} & \mathbf{0} & \mathbf{0} \\
\mathbf{0} & \mathbf{0} & \mathbf{W} \otimes \mathbf{I}_{\mathbf{w}} & \mathbf{0} \\
\mathbf{0} & \mathbf{0} & \mathbf{0} & \mathbf{R} \otimes \mathbf{I}_{\mathbf{e}}
\end{array}\right]
$$

where $\mathbf{W}$ is the variance-covariance matrix for the site-parent interaction effects and $\mathbf{I}_{\mathbf{w}}$ is a unity matrix.

\subsection{Genetic interpretation}

Using model (6), predictions of the parental breeding values and their prediction errors were made. In this study, they are described as:

$$
a_{i}=\mu+2 p_{i}
$$

where $\mu$ is the arithmetic mean of the trait; $a_{i}$ is the prediction of the breeding value for parent $i$ and $p_{i}$ is the predicted parental effect of $i$.

Assuming that epistasis was absent, parental $\left(\sigma_{p}^{2}\right)$, family $\left(\sigma_{f}^{2}\right)$ and residual $\left(\sigma_{e}^{2}\right)$ variances estimated by linear models from the progeny tests were translated into additive genetic variance $\left(\sigma_{A}^{2}\right)$, total genetic variance $\left(\sigma_{G}^{2}\right)$ and phenotypic variance $\left(\sigma_{P}^{2}\right)$ as:

$$
\sigma_{A}^{2}=4 \sigma_{p}^{2} \quad \sigma_{G}^{2}=4\left(\sigma_{p}^{2}+\sigma_{f}^{2}\right) \quad \sigma_{P}^{2}=2 \sigma_{p}^{2}+\sigma_{f}^{2}+\sigma_{e}^{2} .
$$

For the seed orchard, the clone variance $\left(\sigma_{c}^{2}\right)$ and residual error $\left(\sigma_{e}^{2}\right)$ were translated as:

$$
\sigma_{G}^{2}=\sigma_{c}^{2} \quad \sigma_{P}^{2}=\sigma_{c}^{2}+\sigma_{e}^{2}
$$

The corresponding covariances $\sigma_{p_{1} p_{2}}, \sigma_{f_{1} f_{2}}$ and $\sigma_{e_{1} e_{2}}$ were also estimated and translated into $\sigma_{A_{1} A_{2}}, \sigma_{G_{1} G_{2}}$ and $\sigma_{P_{1} P_{2}}$ using the same relationships as shown above.

Based on these genetic variances and covariances, additional genetic parameters were calculated as:

$$
\begin{aligned}
& h^{2}=\frac{\sigma_{A}^{2}}{\sigma_{P}^{2}} \quad H^{2}=\frac{\sigma_{G}^{2}}{\sigma_{P}^{2}} \quad C V_{A}=100 \frac{\sigma_{A}}{\mu} \quad C V_{G}=100 \frac{\sigma_{G}}{\mu} \\
& r_{A_{1} A_{2}}=\frac{\sigma_{A_{1} A_{2}}}{\sigma_{A_{1}} \sigma_{A_{2}}} \quad r_{G_{1} G_{2}}=\frac{\sigma_{G_{1} G_{2}}}{\sigma_{G_{1}} \sigma_{G_{2}}} \quad r_{P_{1} P_{2}}=\frac{\sigma_{P_{1} P_{2}}}{\sigma_{P_{1}} \sigma_{P_{2}}}
\end{aligned}
$$

where $h^{2}$ and $H^{2}$ are narrow- and broad-sense heritabilities; $C V_{A}$ and $C V_{G}$ are the percentage coefficients of additive and total genetic variation, respectively; and $r_{A_{1} A_{2}}, r_{G_{1} G_{2}}$, and $r_{P_{1} P_{2}}$ are the additive genetic, total genetic and phenotypic correlation coefficients, respectively, estimated between $\mathrm{DBH}$ and $\mathrm{GA}_{\mathrm{ub}}$. A log-likelihood ratio test was done to see if genetic correlations were significantly different from zero. The genetic correlations between progeny trials were used as a measurement of $\mathrm{G} \times \mathrm{E}$ interaction, where a correlation of unity indicates the absence of an interaction. Standard errors of genetic parameters were estimated by ASReml [8], using the Taylor series expansion.

Accuracy $\left(r_{T I}\right)$, i.e., the correlation between the true and predicted breeding values, was estimated by:

$$
r_{T I}=\frac{\sigma_{I}}{\sigma_{A}}=\sqrt{\frac{\sigma_{A}^{2}-\frac{1}{n} \sum_{i=1}^{n} P E_{i}^{2}}{\sigma_{A}^{2}}}
$$

where $\sigma_{1}$ is the standard deviation of the predicted breeding values and $P E_{i}$ is the prediction error of the $i$-th breeding value $(i=1$ to $n$ ).

Backward selections of parents were made for each trait separately by using the genetic parameters estimated in this study. Direct genetic gain for trait $1\left(\Delta G_{1}\right)$ as well as correlated response in trait 2 when selecting for trait $1\left(\Delta G_{2 \mid 1}\right)$ was predicted as:

$$
\Delta G_{1}=i r_{T I(1)} \sigma_{A_{1}} \quad \Delta G_{2 \mid 1}=i r_{T I(2)} r_{A_{1} A_{2}} \sigma_{A_{1}}
$$

where $i$ is the standardised selection intensity. 
Table II. Arithmetic means, genetic parameters and trait correlations for Norway spruce diameter at breast height (DBH) and grain angle under bark $\left(\mathrm{GA}_{\mathrm{ub}}\right)$ at each site. Standard errors are given in parentheses. $\sigma_{P}, \sigma_{G}, \sigma_{A}:$ phenotypic, total genetic and additive genetic variance; $C V_{A}$, $C V_{G}$ : coefficient of additive and total genetic variation; $h^{2}, H^{2}$ : narrow- and broad-sense heritabilities; $r_{P}, r_{G}, r_{A}:$ phenotypic, total genetic and additive genetic correlations between $\mathrm{DBH}$ and $\mathrm{GA}_{\mathrm{ub}}$.

\begin{tabular}{|c|c|c|c|c|c|}
\hline & Vetlanda & Tönnersjö & Lönsboda & All progeny tests & Maglehem \\
\hline \multicolumn{6}{|c|}{ DBH (mm) } \\
\hline Mean & $144(1)$ & $142(1)$ & $135(2)$ & $141(1)$ & $291(3)$ \\
\hline$\sigma_{P}$ & $37(2)$ & $36(2)$ & $48(3)$ & $38(1)$ & $55(6)$ \\
\hline$C V_{A}(\%)$ & $13(5)$ & $10(4)$ & $17(6)$ & $12(4)$ & - \\
\hline$C V_{G}(\%)$ & $17(5)$ & $10(6)$ & $17(6)$ & $14(4)$ & $10(3)$ \\
\hline$h^{2}$ & $0.25(0.08)$ & $0.16(0.06)$ & $0.23(0.08)$ & $0.18(0.05)$ & - \\
\hline$H^{2}$ & $0.45(0.11)$ & $0.16(0.10)$ & $0.23(0.08)$ & $0.24(0.06)$ & $0.28(0.07)$ \\
\hline \multicolumn{6}{|c|}{$\mathrm{GA}_{\mathrm{ub}}\left(^{\circ}\right)$} \\
\hline Mean & $2.11(0.05)$ & $1.55(0.04)$ & $1.47(0.06)$ & $1.76(0.03)$ & $1.84(0.10)$ \\
\hline$\sigma_{P}$ & $1.41(0.10)$ & $1.16(0.08)$ & $1.32(0.11)$ & $1.30(0.07)$ & $1.85(0.18)$ \\
\hline$\sigma_{G}$ & $1.00(0.27)$ & $0.92(0.22)$ & $0.87(0.27)$ & $0.93(0.20)$ & $0.92(0.31)$ \\
\hline$\sigma_{A}$ & $0.87(0.26)$ & $0.65(0.23)$ & $0.87(0.27)$ & $0.78(0.22)$ & - \\
\hline$h^{2}$ & $0.38(0.10)$ & $0.32(0.10)$ & $0.44(0.11)$ & $0.36(0.08)$ & - \\
\hline$H^{2}$ & $0.50(0.11)$ & $0.63(0.12)$ & $0.44(0.11)$ & $0.50(0.08)$ & $0.24(0.06)$ \\
\hline \multicolumn{6}{|c|}{ Correlations between DBH and $\mathrm{GA}_{\mathrm{ub}}$} \\
\hline$r_{P}$ & $0.15(0.04)$ & $0.07(0.04)$ & $0.06(0.05)$ & $0.10(0.03)$ & - \\
\hline$r_{G}$ & $0.44(0.16)$ & $0.43(0.26)$ & $0.26(0.23)$ & $0.38(0.15)$ & - \\
\hline$r_{A}$ & $0.38(0.20)$ & $0.25(0.25)$ & $0.26(0.23)$ & $0.37(0.19)$ & - \\
\hline
\end{tabular}

\section{RESULTS}

The overall progeny trial series grain angle was $1.76^{\circ}$ and mean DBH was $141 \mathrm{~mm}$. The individual progeny trials had $\mathrm{GA}_{\mathrm{ub}}$ means in the range $1.47^{\circ}-2.11^{\circ}$ and $\mathrm{DBH}$ means in the range 135-144 $\mathrm{mm}$ (Tab. II). The Maglehem seed orchard produced stems with a mean $\mathrm{GA}_{\mathrm{ub}}$ of $1.84^{\circ}$ and mean $\mathrm{DBH}$ of $291 \mathrm{~mm}$.

Each site was analysed separately and genetic parameters were estimated for each trait within each site (Tab. II). Additive genetic standard deviations for $\mathrm{GA}_{\mathrm{ub}}$ were between $0.65^{\circ}$ and $0.87^{\circ}$, while the total genetic standard deviations were in the range $0.87^{\circ}-1.00^{\circ}$. All progeny trials showed substantial narrow-sense heritability for $\mathrm{GA}_{\mathrm{ub}}$ between 0.32 and 0.44 , and broad-sense heritability between 0.44 and 0.63 . In contrast, broad-sense heritability for $\mathrm{GA}_{\mathrm{ub}}$ in the seed orchard was only 0.24 . Both additive and total genetic coefficients of variation for DBH were in the range 0.10-0.17. Narrow-sense heritability values for DBH were in the range $0.16-0.25$, and broadsense heritability in the range $0.16-0.45$.

Additive genetic correlations between trials were fairly high for $\mathrm{DBH}(0.64-0.93)$ and for $\mathrm{GA}_{\mathrm{ub}}$, correlations were even higher (0.97-1.00) (Tab. III). Thus, small $\mathrm{G} \times \mathrm{E}$ interaction was observed for DBH, while virtually none was observed for $\mathrm{GA}_{\mathrm{ub}}$. Genetic correlation values were also estimated between traits measured in the progeny trials and the same traits measured in the seed orchard, thus connecting parents to progenies (Tab. IV). The diameter correlation values $(-0.18-0.30)$ were never significantly different from 0 , while in contrast, the grain angle correlation values were all much higher (0.66-0.84).

The total genetic and additive genetic correlations between $\mathrm{DBH}$ and $\mathrm{GA}_{\mathrm{ub}}$ in each progeny trial and in the joint analysis of all progeny trials were all weakly positive $(0.25-0.44)$, but
Table III. Additive genetic correlations between Norway spruce progeny tests. Breast height diameter and grain angle under bark are given above and below the diagonal, respectively. Standard errors are given in parentheses.

\begin{tabular}{lccc}
\hline & Vetlanda & Tönnersjö & Lönsboda \\
\hline Vetlanda & & $0.82(0.13)$ & $0.93(0.12)$ \\
Tönnersjö & $1.00(0.05)$ & & $0.63(0.20)$ \\
Lönsboda & $0.99(0.06)$ & $0.97(0.06)$ & \\
\hline
\end{tabular}

Table IV. Genetic correlation values between the same trait measured in Norway spruce progeny trials and in the seed orchard. The traits are breast height diameter $(\mathrm{DBH})$ and grain angle under bark $\left(\mathrm{GA}_{\mathrm{ub}}\right)$. Standard errors are given in parentheses.

\begin{tabular}{ccc}
\hline & DBH & $\mathrm{GA}_{\mathrm{ub}}$ \\
\hline Vetlanda & $0.30(0.25)$ & $0.84(0.11)$ \\
Tönnersjö & $-0.18(0.28)$ & $0.70(0.17)$ \\
Lönsboda & $0.05(0.29)$ & $0.66(0.17)$ \\
\hline
\end{tabular}

none were significantly different from 0 at the $5 \%$ probability level (Tab. II).

The data for DBH across all trials were roughly normally distributed, while those for $\mathrm{GA}_{\mathrm{ub}}$ exhibited a small tail consisting of highly left-grained trees (Fig. 1A). Grain angle distributions of family means and the phenotypic grain angle distributions from the separate trials also exhibited this deviation from normal. The joint analysis of the progeny trials (Eq. (6)) was performed in order to predict breeding values for $\mathrm{GA}_{\mathrm{ub}}$ and to estimate overall genetic parameters for each trait (Tab. II). The $\mathrm{GA}_{\mathrm{ub}}$ breeding values were in the range $0.71^{\circ}-3.05^{\circ}$ (Fig. 1B) with prediction errors of $0.32^{\circ}-0.44^{\circ}$ and a mean prediction accuracy $\left(r_{T I}\right)$ of 0.90 . DBH breeding values were in the range 

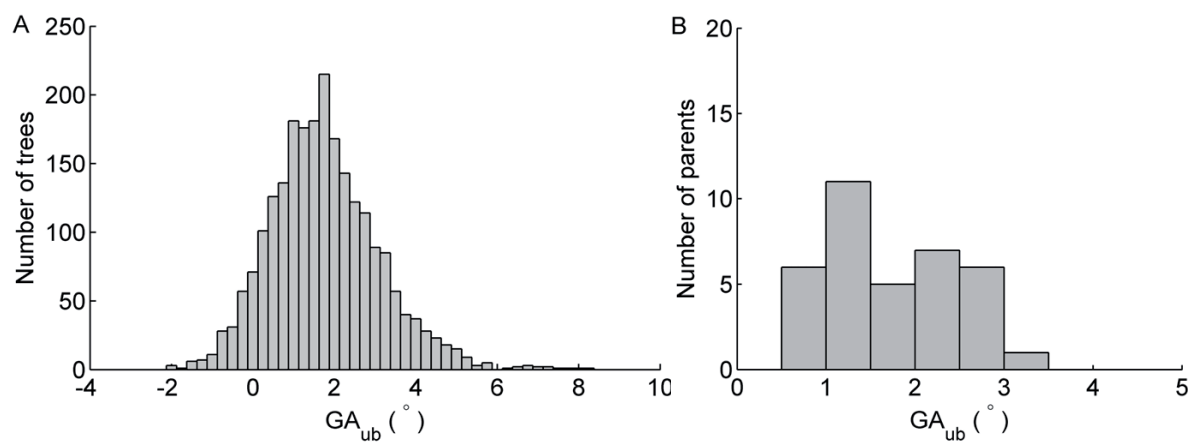

Figure 1. Distribution histograms of individual phenotypic values $(A)$ and parent breeding values $(B)$ for grain angle under bark $\left(\mathrm{GA}_{\mathrm{ub}}\right)$ from all the three Norway spruce progeny trials.

108-165 mm with prediction errors of 8-11 $\mathrm{mm}$ and $r_{T I}$ of 0.85 . The genetic parameters of the joint analysis were in accordance with those of the separate progeny trial analyses.

\section{DISCUSSION}

When investigating grain angle as a potential selection trait, the breeding objective would be to avoid the occurrence of twisting during the drying of sawn studs and not to decrease grain angle per se. In contrast to this study, almost all genetic studies of grain angles in conifers have focused on young trees which probably still produce juvenile wood under bark $[2,7,10,24]$. The great impact of high juvenile wood grain angles on the timber sawn from that portion of the log has been shown repeatedly $[6,25,26]$. However, some Norway spruce trees retain or even increase their left grain angle with each annual ring produced, thus deviating from the normal grain angle development of conifers. Such left-grained trees will produce twist-prone mature wood, as well as twist-prone juvenile wood $[1,18]$. Under the slow growing conditions that prevail in boreal forests, mature wood constitutes a substantial part of the stem at rotation age. Consequently, it is interesting to investigate whether genetic variation in $\mathrm{GA}_{\mathrm{ub}}$ can also be observed in trees which have begun to produce mature wood at breast height.

\subsection{Mean values and genetic parameters}

The mean $\mathrm{GA}_{\mathrm{ub}}$ values of the 28-year-old progeny trials agree well with published estimates in Norway spruce of mean grain angle measured at corresponding cambial ages. The seed orchard, while having a cambial age some 20 years older than the progeny trials, still exhibited a mean $\mathrm{GA}_{\mathrm{ub}}$ similar to that found in the progeny trials. A possible explanation for this could be the very different environment for the seed orchard grafts, with large spacing and rapid growth conditions, factors that have been indicated to promote left grain angle development $[13,19,24]$.

In the progeny trials, heritability values for $\mathrm{GA}_{\mathrm{ub}}$ were higher than those for DBH (Tab. II). Additive genetic standard deviation, as a descriptor of $\mathrm{GA}_{\mathrm{ub}}$ genetic variation, was also substantial and similar at the various sites. The $\sigma_{A}$ estimates of this study were also comparable with those of other studies on Norway spruce $\left(0.5^{\circ}-1.2^{\circ}\right)$, even if the trees of their investigation were considerably younger $[2,10,11]$. The heritabilities and genetic coefficients of variation for DBH could be considered typical at the sites of our study, compared with those compiled from a large number of trials [21]. Broad-sense heritability for $\mathrm{GA}_{\mathrm{ub}}$ in the seed orchard was substantial, albeit lower than that in the progeny trials, while the latter agree well with previous estimates for Norway spruce [2, 10], Scots pine [11] and radiata pine [7]. Other studies of grain angle done in radiata pine and Sitka spruce have obtained even higher estimates for heritability $(>0.5)[4,12,17]$. With only one exception [9], these studies all obtained stronger heritabilities for $\mathrm{GA}_{\mathrm{ub}}$ than for DBH. Furthermore, in most studies the $\mathrm{GA}_{\mathrm{ub}}$ heritabilities have been stronger than those found for height and volume growth $[2,11,17,21,24]$. The genetic control of grain angle development thus seems strong and generally greater than that for growth properties in several conifer species.

The genetic correlations between progeny sites for $\mathrm{GA}_{\mathrm{ub}}$ were very close to unity, suggesting that $\mathrm{G} \times \mathrm{E}$ interactions are very small for this trait (Tab. III). For DBH, corresponding correlations were slightly lower. Most other authors have also observed very small $\mathrm{G} \times \mathrm{E}$ interactions for $\mathrm{GA}_{\mathrm{ub}}$ in Norway spruce, and these were as small as or even smaller than those for $\mathrm{DBH}[2,10]$. Furthermore, the genetic correlation values for between the seed orchard and the different progeny trials were all strong and significant (Tab. IV), while those for DBH were all around zero. The genetic correlations between seed orchards and progeny trials are interesting even though they cannot be considered good estimations of $\mathrm{G} \times \mathrm{E}$ interaction. The greater age of the seed orchard material and greater exposure to environmental disturbances must be mentioned as well as the more intensive establishment and maintenance measures such as grafting, pruning, rougeing and damage inflicted during cone harvests. Moreover, the lack of purely additive breeding values for the seed orchard clones may further diminish estimations of genetic correlations. Even so, the relatively high genetic correlations for $\mathrm{GA}_{\mathrm{ub}}$ are remarkable and imply that grain angle inheritance from parent to progeny is observable, despite all the aforementioned environmental differences and other disturbances. Meanwhile, the low genetic correlations 

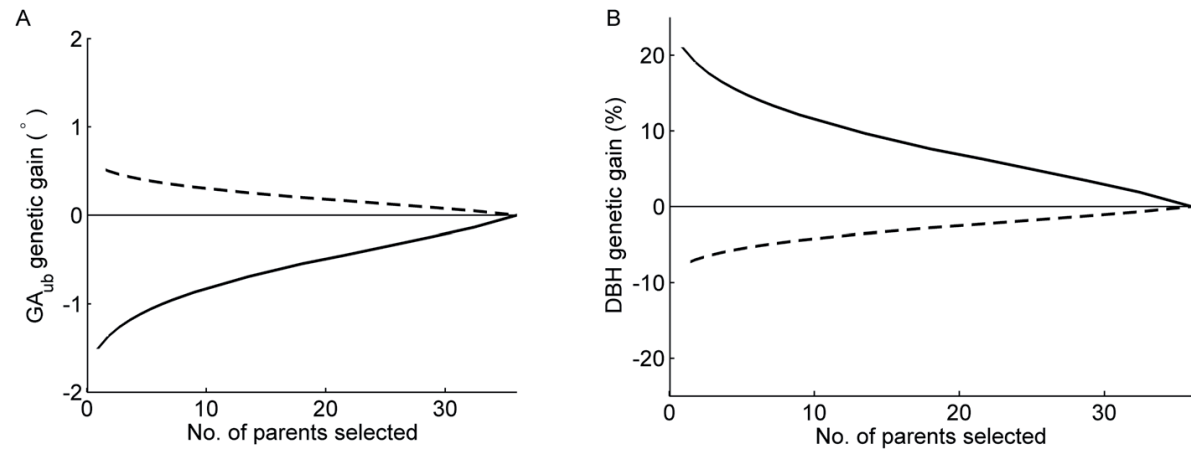

Figure 2. Predicted genetic responses in grain angle under bark $\left(\mathrm{GA}_{\mathrm{ub}}\right)$ and diameter at breast height (DBH) from backward selections in Norway spruce. (A) Direct $\mathrm{GA}_{\mathrm{ub}}$ response to selections for lower $\mathrm{GA}_{\mathrm{ub}}$ (solid line) and indirect $\mathrm{GA}_{\mathrm{ub}}$ response to selections for higher $\mathrm{DBH}$ growth (dashed line). (B) Direct DBH response to selections for high DBH growth (solid line) and indirect DBH response to selections for lower $\mathrm{GA}_{\mathrm{ub}}$ (dashed line).

for DBH between progeny trials and the seed orchard imply that DBH observed in the seed orchard cannot be regarded as the same trait as DBH observed in the progeny trials.

\subsection{Selection gains}

To illustrate the potential use of the genetic parameters in a hypothetical breeding situation, backward selections were made among the 36 parents. Selection of the five parents with the lowest $\mathrm{GA}_{\mathrm{ub}}$ breeding values $(i=1.542)$ would confer a $\mathrm{GA}_{\mathrm{ub}}$ decrease upon progeny of at least $1^{\circ}$ (Fig. 2A). On the other hand, additive genetic and total genetic correlations between $\mathrm{DBH}$ and $\mathrm{GA}_{\mathrm{ub}}$ were positive for all progeny trials (Tab. II), suggesting that breeding for lower grain angles would also confer reduced diameter growth. Selection of the five parents with the lowest $\mathrm{GA}_{\mathrm{ub}}$ breeding values caused an indirect genetic loss in DBH of approximately 5\% (Fig. 2B). This should be compared with a selection of the five parents with the highest DBH breeding values, which would yield a genetic gain of about 15\% in DBH growth. Conversely, a selection of the five parents for best DBH growth, completely disregarding grain angle, could indirectly increase the mean grain angle by almost $0.5^{\circ}$ (Fig. 2A).

The indirect genetic gain estimates must be interpreted with great caution, as the standard errors of the genetic correlations were quite high and never significantly different from zero. Earlier estimates of genetic correlations between diameter and grain angle in Norway spruce have been weak and inconclusive $(-0.5<r<0.5)$, with high standard errors $[3,9,11]$. While this topic deserves further study, there is no evidence for strong, unfavourable genetic correlation between these traits. A suggestion would be to use economic weights to formulate reasonable breeding priorities.

\subsection{Possible genetic control over the occurrence of left-grained trees?}

Grain angles in Norway spruce have been shown to culminate approximately at the 10th annual ring at a value of about

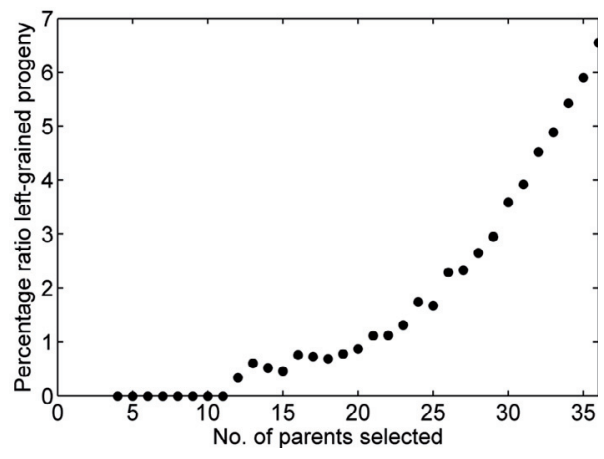

Figure 3. Percentage of potentially left-grained Norway spruce progenies of crosses between selected parents. The parents were selected for having the lowest breeding values for grain angle under bark.

$3^{\circ}$ and grain angle development in later years can be considered as largely linear [5,23]. One may therefore speculate that the relatively old progeny-trial trees in this study with a $\mathrm{GA}_{\mathrm{ub}}$ above $4^{\circ}$ could be left-grained, consequently producing wood with undesirable shape stability properties [18]. Seven percent of the progeny trees in our material fell into that category and, interestingly, these trees comprised the left-grained tail of the observed phenotypic $\mathrm{GA}_{\mathrm{ub}}$ distribution (Fig. 1A). Similar deviations from the normal distribution were also observed for the family $\mathrm{GA}_{\mathrm{ub}}$ means and have also been reported for family means in radiata pine [24].

Even if none of the evaluated parents obtained $\mathrm{GA}_{\mathrm{ub}}$ breeding values over $4^{\circ}$ (Fig. 1B), the breeding values and additive genetic variation still suggest that some parents have a higher risk of producing left-grained offspring than others. As mentioned earlier, the possible $\mathrm{GA}_{\mathrm{ub}}$ genetic reductions should be more than $1^{\circ}$ when selecting the five parents out of 36 with the lowest $\mathrm{GA}_{\mathrm{ub}}$ breeding values. Considered as an absolute value this reduction may seem small and one might also question what effect it has on the occurrence of left-grained progeny trees. Still, the ratios of potentially left-grained progenies of crosses between the selected parents (Fig. 3) illustrate the importance of this change. Already, in a selection portion of 11 
out of 36 parents $(i=1.120)$ with the lowest $\mathrm{GA}_{\mathrm{ub}}$ breeding values, none of the resulting progenies had a $\mathrm{GA}_{\mathrm{ub}}$ of over $4^{\circ}$. This would suggest the possibility of completely abolishing the occurrence of left-grained stems by a single selection, and that short-term gains in shape stability could be made by genetic rougeing of seed orchard parent clones with high $\mathrm{GA}_{\mathrm{ub}}$ breeding values.

Still, this can only be considered a hint, as the ratios are based on two measurements on a single tree and these may have large errors. Moreover, grain angles in a single annual ring do not completely reveal the entire grain angle development of the tree. To efficiently address the question of trees with left-grained development, measurements should be made on several annual rings of different cambial ages.

\section{CONCLUSIONS}

In conclusion, the $\mathrm{GA}_{\mathrm{ub}}$ genetic variation was substantial and the high heritabilities indicate that genetic control of grain angles, also in Norway spruce mature wood, is stronger than that of $\mathrm{DBH}$ and appears to be stronger than that of growth traits in general. The negligible $\mathrm{G} \times \mathrm{E}$ interaction for $\mathrm{GA}_{\mathrm{ub}}$ among progeny trials suggests that selection to lower $\mathrm{GA}_{\mathrm{ub}}$ would require evaluation at only one site, provided environmental differences among sites are not larger than those found here. Moreover, the genetic $\mathrm{GA}_{\mathrm{ub}}$ correlation between progeny and parents was substantial, further demonstrating the strength of mature wood grain angle heritability, even when large environmental and age differences were introduced. This indicates that seed orchard data can be useful for ranking genotypes with respect to grain angle.

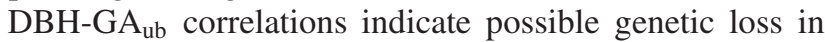
$\mathrm{DBH}$ growth when breeding for lower $\mathrm{GA}_{\mathrm{ub}}$, but these estimates are weak and should be investigated further.

No parent $\mathrm{GA}_{\mathrm{ub}}$ breeding values were above $4^{\circ}$. However, the ratio of progeny trees with measured $\mathrm{GA}_{\mathrm{ub}}$ values of $4^{\circ}$ or more was $7 \%$. This ratio was decreased to $0 \%$ when making selections of 11 out of 36 parents ranked for low $\mathrm{GA}_{\mathrm{ub}}$. The ratio estimations may have large errors, but the trend still suggests that substantial reductions of the ratio of trees with large mature wood left-grain angles could be made by excluding parents with high $\mathrm{GA}_{\mathrm{ub}}$ breeding values.

Acknowledgements: Profound thanks are given to Mats Berlin and Harald Säll for useful discussions, and especially to Tim Mullin for his comments on the manuscript. We also highly appreciated the technical assistance of Skogforsk in Ekebo, and Gudmund Ahlberg in particular. This study was done within the framework of The Research School of Forest Genetics and Tree Breeding and was also supported by the host company of the first author, Bergvik Skog.

\section{REFERENCES}

[1] Bäckström M., Johansson M., 2006. Analytical model of twist in Norway spruce (Picea abies) timber, Scand. J. For. Res. 21: 54-62.

[2] Costa E Silva J., Borralho N.M.G., Wellendorf H., 2000. Genetic parameter estimates for diameter growth, pilodyn penetration and spiral grain in Picea abies (L.) Karst., Silvae Genet. 49: 29-36.
[3] Costa E Silva J., Borralho N.M.G., Wellendorf H., 2000. Prediction of breeding values and expected genetic gains in diameter growth, wood density and spiral grain from parental selection in Picea abies (L.) Karst., Silvae Genet. 49: 102-109.

[4] Cown D.J., Ball R.D., Riddell M.J.C., 2004. Wood density and microfibril angle in 10 Pinus radiata clones: Distribution and influence on product performance, N.Z. J. For. Sci. 34: 293-315.

[5] Danborg F., 1994. Spiral grain in plantation trees of Picea abies, Can. J. For. Res. 24: 1662-1671.

[6] Forsberg D., 1999. Warp, in particular twist, of sawn wood of Norway spruce (Picea abies), Ph.D. thesis, Silvestria, Acta Univ. Agric. Sueciae, 143 p.

[7] Gapare W., Hathorn A., Kain D., Matheson C., Wu H., 2007. Inheritance of spiral grain in the juvenile core of Pinus radiata, Can. J. For. Res. 37: 116-127.

[8] Gilmour A.R., Gogel B.J., Cullis B.R., Welham S.J., Thompson R., 2003. ASReml user guide, 1st ed., VSN International, $267 \mathrm{p}$.

[9] Hannrup B., Cahalan C., Chantre G., Grabner M., Karlsson B., Le Bayon I., Lloyd Jones G., Müller U., Pereira H., Carlos Rodrigues J., Rosner S., Rozenberg P., Wilhelmsson L., Wimmer R., 2004. Genetic parameters of growth and quality traits in Picea abies, Scand. J. For. Res. 19: 14-29.

[10] Hannrup B., Grabner M., Karlsson B., Müller U., Rosner S., Wilhelmsson L., Wimmer R., 2002. Genetic parameters for spiralgrain angle in two 19-year-old clonal Norway spruce trials, Ann. For. Sci. 59: 551-556.

[11] Hannrup B., Säll H., Jansson G., 2003. Genetic parameters for spiral grain in Scots pine and Norway spruce, Silvae Genet. 52: 215-220.

[12] Hansen J.K., Roulund H., 1998. Genetic parameters for spiral grain in two 18-year-old progeny trials with sitka spruce in Denmark, Can. J. For. Res. 28: 920-931.

[13] Harris J.M., 1989. Spiral grain and wave phenomena in wood formation, Springer-Verlag, Berlin, $214 \mathrm{p}$.

[14] Johansson G., Kliger R., Perstorper M., 1994. Quality of structural timber-product specification system required by end-users, Holz. Roh. Werkst. 52: 42-48.

[15] Johansson M., Perstorper M., Kliger R., Johansson G., 2001. Distortion of Norway spruce timber. Part 2. modelling twist, Holz. Roh-Werkst. 59: 155-162.

[16] Krempl H., 1970. Untersuchungen über den Drehwuchs bei Fichte, vol. 89, Mitt. Forstl. Bundes-Versuchanstalt, Wien, In German, $117 \mathrm{p}$.

[17] Lindström H., Harris P., Sorensson C.T., Evans R., 2004. Stiffness and wood variation of 3-year old Pinus radiata clones, Wood Sci. Technol. 38: 579-597.

[18] Ormarsson S., 1999. Numerical analysis of moisture-related distortions in sawn timber, Ph.D. thesis, Department of structural mechanics, Chalmers Univ. Technol., 214 p.

[19] Pape R., 1999. Influence of thinning on spiral grain in Norway spruce grown on highly productive sites in southern Sweden, Silva Fenn. 33: 3-12.

[20] Prescher F., Lindgren D., Varghese M., 2004. Genetic thinning of clonal seed orchards using linear deployment, In: Li B., McKeand S. (Eds.), IUFRO Forest Genetics Meeting Proceedings, pp. 232240. 
[21] Rosvall O., Jansson G., Andersson B., Ericsson T., Karlsson B., Sonesson J., Stener L.-G., 2001. Genetiska vinster i nuvarande och framtida fröplantager och klonblandningar, Redogörelse 1, Skogforsk, $41 \mathrm{p}$.

[22] Rozenberg P., Cahalan C., 1997. Spruce and wood quality: Genetic aspects (a review), Silvae Genet. 46: 270-279.

[23] Säll H., 2002. Spiral grain in Norway spruce, Ph.D. thesis, Acta Wexionensia, Växjö Univ., 163 p.
[24] Sorensson C.T., Burdon R.D., Cown D.J., Jefferson P.A., Shelbourne C.J.A., 1997. Incorporating spiral grain into New Zealand's radiata pine breeding programme, In: Burdon R.D., Moore J.M. (Eds.), IUFRO '97 genetics of radiata pine , pp. 180191.

[25] Stevens W.C., Johnston D.D., 1960. Distortion caused by spiralled grain, Timber Technology 68: 217-218.

[26] Woxblom L., 1999. Warp of sawn timber of Norway spruce in relation to end-user requirements, Ph.D. thesis, Silvestria, Acta Univ. Agric. Sueciae, 138 p. 